\title{
Kessler Psychological Distress Scale: Internal Structure and Relation to Other Variables
}

\author{
Brenda Fernanda Pereira da Silva ${ }^{1}$ \\ Lais Santos-Vitti ${ }^{2}$ \\ André Faro ${ }^{1}$ \\ ${ }^{1}$ Universidade Federal do Sergipe, São Cristóvão, Sergipe, Brasil \\ ${ }^{2}$ Pontificia Universidad Católica, Campinas, São Paulo, Brasil
}

\begin{abstract}
This study aimed to present validity evidence based on internal structure of the Kessler Scale of Psychological Distress (K10), to show its relations with the Perceived Stress Scale (PSS-10), and to present a social distribution of distress in the present sample. Participated in the study 717 residents of Aracaju, State of Sergipe, by means of household data collection. A sociodemographic questionnaire, K10, and PSS-10 were used as instruments. Exploratory Factor Analysis was performed using the Factor software, which indicated the scale unidimensionality, explaining $69.9 \%$ of the variance. Cronbach's alpha was 0.93 , and the model adjustment indices were satisfactory. A positive and statistically significant association between K10 and PSS-10 was observed. Regarding the social distribution, the levels of distress were higher in women, patients with chronic diseases, users of controlled drugs, and unemployed participants. It was concluded that K10 presented robust psychometric properties for the detection of distress in general population.

Keywords: test validity; psychometrics; distress; screening
\end{abstract}

Escala Kessler de Distresse Psicológico: Estrutura Interna e Relação com Outras Variáveis

\section{Resumo}

Este estudo objetivou apresentar evidências de validade da estrutura interna da Escala Kessler de Distresse Psicológico (K10), apontar sua relação com a Escala de Estresse Percebido (PSS-10) e apresentar relações entre o distresse e variáveis sociodemográficas (distribuição social) na amostra. Participaram do estudo 717 residentes do município de Aracaju, Sergipe, por meio de coleta domiciliar. Utilizaram-se questionário sociodemográfico, a K10 e a PSS-10 como instrumentos. Realizou-se análise fatorial exploratória com o software Factor, que indicou a unidimensionalidade fatorial da escala, explicando 69,9\% da variância. O alfa de Cronbach foi 0,93 e os índices de ajuste do modelo foram satisfatórios. Observou-se uma associação positiva e estatisticamente significativa entre a K10 e a PSS-10. Quanto à distribuição social, os níveis de distresse foram maiores em mulheres, portadores de doenças crônicas, usuários de medicamentos controlados e desempregados. Concluiu-se que a K10 apresentou propriedades psicométricas robustas para rastreamento do distresse na população geral.

Palavras-chave: validade do teste; psicometria; distresse; rastreamento

\section{Escala Kessler de Malestar Psicológico: Estructura Interna y Relación con Otras Variables}

\begin{abstract}
Resumen
Este estudio tuvo como objetivo presentar evidencias de validez basadas en la estructura interna de la Escala Kessler de Malestar Psicológico (K10), señalar sus relaciones con la Escala de Estrés Percibido (PSS-10) y las relaciones actuales entre el malestar y las variables sociodemográficas (distribución social) en la presente muestra. Participaron del estudio 717 residentes del municipio de Aracaju, provincia de Sergipe, por medio de la recolección domiciliaria. Se utilizaron el cuestionario sociodemográfico K10 y PSS-10 como instrumentos. El Análisis Factorial Exploratorio se realizó a partir del software Factor, que indicó la unidimensionalidad factorial de la escala, explicando el 69,9\% de la varianza. El alfa de Cronbach fue de 0,93 y los índices de ajuste del modelo fueron satisfactorios. Se observó una asociación positiva y estadísticamente significativa entre K10 y PSS-10. En cuanto a la distribución social, los niveles de malestar fueron mayores en mujeres, portadores de enfermedades crónicas, usuarios de medicamentos controlados y desempleados. Se concluyó que la K10 presenta propiedades psicométricas robustas para el rastreo del distrés en la población general.
\end{abstract}

Palabras clave: validez del test; psicometría; malestar; rastreo

\section{Introduction}

Stress has been pointed out as a risk factor for the development of numerous chronic diseases due to the biochemical changes it causes in the human body (Lee, Kim, \& Choi, 2015). This phenomenon can be understood as the product of a cognitive assessment that triggers processes of regulation in physiological, behavioral, and emotional functioning, which leads to a state of search for an adaptive response (Faro, 2015a). Stress cannot be considered inherently harmful to health, since its detrimental action on individual adjustment occurs only when the stress load extrapolates a person's prior ability to adapt to adversity (Faro \& Pereira, 2013; 
Lee et al., 2015). Thus, as far as illness is concerned, the facet of stress related to adaptive overload stands out, in this case, distress.

Distress is related to the condition of attrition of the adaptive system, in which the adjustment resources mobilized by the individual to face the stressor are not able to promote adaptation, failing to restore physical and mental homeostasis (Drapeau, Marchand, \& Beaulieu-Prévost, 2012). Therefore, distress has been pointed as a situation of excessive and chronic stress, which subjects the individual to vulnerability to disease and psychic suffering, due to the excess of adaptive overload, being a consistent construct to evaluate illnesses in individuals, groups, and populations (Anderson et al., 2013; Lee et al., 2015).

Distress is one of the most relevant mental health indicators to monitor the vulnerability to the development of common mental disorders such as depression and anxiety (Anderson et al., 2013; Bougie, Arim, Kohen, \& Findlay, 2016; Drapeau et al., 2012; Easton, Safadi, Wang, \& Hasson, 2017). Among the existing psychological distress measures, the Kessler Psychological Distress Scale (K10) has been widely used around the world, especially due to its high accuracy, validity, and internal consistency (Kessler et al., 2002; Kessler et al., 2003; Mouzon, Taylor, Nguyen, \& Chatters, 2016).

The K10 was originally developed by Kessler and collaborators in 2002 in order to develop a short scale of screening for non-specific psychological distress for use by the United States National Health Interview Survey (NHIS), which needed a brief and accurate instrument for screening for general symptoms of common mental disorders (Kessler et al., 2003). It is composed of 10 questions about the frequency with which respondents presented symptoms of psychological distress in the last 30 days, with items that include behavioral, emotional, and cognitive manifestations of distress (Kessler et al., 2002; Kessler et al., 2003). The K10 has a onedimensional factorial structure and its final score is the product of the sum of the responses of all items. The items range from 1 (never) to 5 (always) on a Likert type scale, with a total score between 10 and 50 points, and the higher the score, the stronger the presence of distress symptoms.

K10 was an instrument used in studies conducted in several countries, with different samples, such as South Africa (Andersen et al., 2011), Argentina (Brenlla \& Aranguren, 2010), Australia (Anderson et al., 2013; Brooks, Beard, \& Steel, 2006; Sunderland, Mahoney, \& Andrews, 2012), Canada (Bougie et al., 2016; Caron et al., 2012; Sampasa-Kanyinga, Zamorski, \& Colma, 2018; Vasiliadis, Chudzinski, Gontijo-Guerra, \& Préville, 2015), the West Bank (Easton et al., 2017), Japan (Furukawa et al., 2010; Sakurai, Nishi, Kondo, Yanagida, \& Kawakami, 2011), the Netherlands (Donker et al., 2010), Portugal (Pereira et al., 2017), Mexico (Terrez, Salcedo, Estrada, Romero, \& Sotres, 2011), among others. Currently, K10 is translated into more than 15 different languages, having been validated in most of the countries where it is used (National Comorbidity Survey, n. d.).

K10 presented excellent Cronbach's alpha $(\alpha)$ (0.93) in its initial validation (Kessler et al., 2002). It even showed an alpha between 0.88 and 0.94 in countries such as Argentina (Brenlla \& Aranguren, 2010), Canada (Sampasa-Kanyinga et al., 2018), the West Bank (Easton et al., 2017), South Africa (Andersen et al., 2011), France (Arnaud et al., 2010), Japan (Sakurai et al., 2011), the Netherlands (Donker et al., 2010), Mexico (Terrez et al., 2011), and Portugal (Pereira et al., 2017), showing good psychometric quality overall. Regarding its dimensionality, most studies show a consensus on its unifactorial structure (Drapeau et al., 2012), although some investigations showed evidence for a structure of 2 to 4 factors (Arnaud et al., 2010; Brooks et al., 2006; Sampasa-Kanyinga et al., 2018; Sunderland et al., 2012), revealing some discrepancies in its factor structure (Easton et al., 2017). In the case of K10, although some studies found that a singlefactor structure represents more adequately the latent construct of the scale, there are authors who claim that a possible multidimensionality would be more positive for better identification of symptoms in their subdomains (Arnaud et al., 2010; Brooks et al., 2006). It is noteworthy that the difference in the number of factors implies the precision and variability of the construct being measured (Pasquali, 2011).

Despite having been translated into Brazilian Portuguese and having already been used in some studies in Brazil to track symptoms (Gomes-Oliveira, Gorenstein, Lotufo Neto, Andrade, \& Wang, 2012; Leal et al., 2012; Mota \& Faro, 2018), the K10 still lacks evidence of psychometric validity and factorial structure in Brazilian samples. Considering its brevity, precision, and robust psychometric properties that make it a tool indicated in health questionnaires for the general population (Kessler et al., 2003), it is considered relevant to conduct an Exploratory Factor Analysis (EFA), in order to investigate the factorial structure of the K10 in Brazil, as well as to compare it with international findings. 
EFA is a psychometric procedure that enables the identification of the most appropriate factor structure for a given instrument, i.e., the one that best represents the observed variable (Damásio, 2012). Such representation is obtained from the analysis of the covariance between the items and, when these items share a common variance, it is understood that they belong to the same factor, as they are influenced by the same construct. (Damásio, 2012). Considering the need to search for validity evidence in measures in Psychology, it is understood that EFA is a good tool for this, being related to the construction and validation of psychological instruments (Laros, 2012).

Validity concerns the quality, suitability and usefulness of a test for a specific purpose. Validity evidence based on the internal structure and on the relationship with other variables are types of validity that aim to ensure the aforementioned characteristics in a test (Sireci \& Sukin, 2013). When performing the K10 EFA, it is expected to obtain a factorial structure that better reflects this measure in relation to a Brazilian population. Understanding the differences between samples or locations allows for more representative and accurate data on the researched population, in addition to allowing comparisons with other samples.

In this sense, it is important to track the social distribution of distress in a local sample, i.e., relating distress to sociodemographic characteristics that can help to identify the profile of people in psychological suffering. Other studies have already conducted this analysis, indicating the relevance of assessing the differences in levels of distress according to the sociodemographic profile of a population, in order to obtain a better understanding of the variability of the phenomenon in society (Mota \& Faro, 2018; St-Pierre, Sinclair, Elgbeili, Bernard, \& Dancause, 2019; Vasiliadis et al., 2015; Zenebe \& Necho, 2019).

Furthermore, it is also considered relevant to correlate the K10 with the Perceived Stress Scale (PSS-10), since it is one of the most widely used measures to assess stress and it is evaluated as the gold standard (Faro, 2015b). The K10 and the PSS are two widely recognized scales for studying distress and stress. Both are short health screening measures aimed at measuring similar constructs, which makes it interesting to relate them. There are several studies in several countries that attest to the validity and reliability of PSS (Baik et al., 2019; Faro, 2015b; Klein et al., 2016; Reis, Hino, \& Rodriguez-Añez, 2010), therefore, it is believed that the analysis of the evidence of validity of the K10 in relation to the PSS-10 becomes pertinent.

The main objective of this investigation was to analyze validity evidence of the Kessler Scale of Psychological Distress (K10) in a Brazilian sample, with specific objectives: (a) to present the internal structure of the scale, by means of exploratory factor analysis, as well as its internal consistency; (b) to point out the correlation between the K10 and the Perceived Stress Scale in its short version (PSS-10), in order to assess validity evidence based on the relationship with other variables; and, finally, (c) to present the social distribution of distress in the present sample according to the variables sex, presence of chronic disease, use of controlled medication, and presence of paid work.

\section{Method}

\section{Participants}

A total of 717 adults of both sexes participated, with ages ranging from 18 and 63 years $(M=36.0 ; S D$ = 12.79), living in the city of Aracaju, State of Sergipe. Data collection occurred at home and in a systematic way, controlling aspects such as sex (search for the 50/50 ratio), visits by day of the week (including weekends), shifts (morning, afternoon, evening), and households (two households were skipped at each application). The sampling was randomized, so that three neighborhoods were selected in each census region of the municipality (Center / East, North, South, and West) and, in each neighborhood, avenues or main streets were drawn, in a total of 15 neighborhoods. It is worth mentioning that only one resident in each residence participated in the collection, excluding visitors and workers, as well as people with disabling physical conditions or mental disorders (self-reported).

The sample consisted of $55.9 \%$ women $(n=401)$. Regarding the race / ethnicity declaration, $72.0 \%$ of the respondents $(n=516)$ considered themselves nonwhite (including yellow, indigenous, brown, Native American, black, and others) and 28.0\% $(n=201)$ identified themselves as whites. Specifically, $45.3 \%$ ( $n$ $=325)$ considered themselves brown, $28 \%(n=201)$ white, $13.7 \%(n=98)$ black, and $13 \%(n=93)$ as others. Regarding health-related variables, $80.9 \%(n=580)$ of the sample denied having any chronic disease and $81.6 \%(n=585)$ declared that they did not use controlled drugs. In addition, $79.5 \%(n=570)$ of the participants declared that they worked in paid work at the time of the investigation. 


\section{Instruments}

A sociodemographic questionnaire was used, consisting of the variables sex (female and male), age (in years), skin color (white and non-white), self-reported chronic disease (yes and no), use of controlled medication (yes and no), and performing some type of paid work (yes and no) at the time of data collection.

The Kessler Psychological Distress Scale - K10 (Kessler et al., 2002) consists of 10 items that investigate signs of psychological distress, such as depressive and anxious symptoms, in the last 30 days, using a 5-point Likert scale as a response model, ranging from 1 (never) to 5 (always). Usually, the K10 is assessed with a total score; however, it is also possible to analyze it according to strata of symptom severity, namely: scores of $10-15$ points indicate mild distress, $16-21$ points indicate moderate distress, 22-29 indicate high distress, and 30-50 points indicate very high distress (Andrews \& Slade, 2001).

The Perceived Stress Scale, in its reduced version (PSS-10), comprises 10 items and consists of a single factor scale, composed of 6 positive and 4 negative items, answered from a 5-point Likert scale, ranging from 0 (never) to 4 (always). The final score is between 0 and 56 points and, the higher the score, the greater the stress perceived by the individual in the last 30 days. In the present study, the version translated and adapted into Portuguese by Machado, Damásio, Borsa and Silva (2010) was used.

\section{Procedures and ethical aspects}

Fifteen interviewers went to the field fulfilling the parameters established for the collection, having been previously trained and supervised in the field. The survey was presented to the respondents and the Informed Consent Form (ICF) was signed in 2 copies. Human research legislation was complied with; therefore the investigation was approved by the Research Ethics Committee of the Federal University of Sergipe under number (CAAE: 0165.0.107.000-11).

\section{Data analysis}

Initially, descriptive statistics were performed in the SPSS - version 20, in order to obtain means and percentages to characterize the sample. Next, the K10 Exploratory Factor Analysis (EFA) was performed using the FACTOR software. This software consists of an autonomous, comprehensive and free program to perform exploratory and semi-confirmatory factor analysis models. We chose to use it due to its degree of technical development comparable to other commercial pieces of software, as well as due to the robust analyses it offers (Ferrando \& Lorenzo-Seva, 2017). The rotation method used was Promin, which allows for the oblique rotation of items, to maximize the simplicity of the factor (Lorenzo-Seva, 2013).

To evaluate the quality of the final model generated, 7 indexes were analyzed. The Root Mean Square Error of Approximation (RMSEA) is an adjustment indicator considered acceptable below 0.08 , with an upper limit of confidence interval of 0.10 . The Non-Normed Fit Index (NNFI), also known as the Tucker-Lewis Index (TLI) in other pieces of software, and the Comparative Fit Index (CFI) are also adjustment indicators considered acceptable above 0.90. Cronbach's alpha $(\alpha)$, a factor reliability indicator, was considered acceptable at 0.70 (Damásio \& Dutra, 2017). Unidimensionality indicators of the scale were also obtained, namely: Unidimensional Congruence (UniCo) and Explained Common Variance (ECV), which indicate the proximity to unidimensionality and the proportion of variance explained by the first factor, and Mean of Item Residual Absolute Loadings (MIREAL), measure of residuals or errors when considering only 1 factor. UniCo values above 0.95 , ECV values above 0.85 and MIREAL values below 0.30 are considered acceptable (Damásio \& Dutra, 2017). Regarding factor retention, results of the Parallel Analysis (PA) were observed, which is consolidated in the international literature as the most reliable criterion (Damásio, 2012).

Finally, with the help of SPSS, Spearman correlations (e) were also performed to investigate the validity evidence based on the relationship with other variables between the K10 and the PSS-10, as well as to correlate the total K10 score with the age of the participants. The Mann-Whitney U test was also applied to compare the mean between the variables sex, race / ethnicity, presence of chronic disease, use of controlled medications, and performing paid work. It is worth mentioning that these non-parametric analyses were chosen due to the non-normal distribution of the K10 score variable $($ Skewness $=1.230$ and Kurtosis $=1.235)$ in this sample. In addition, two variables were dichotomized (skin color and work) for analysis purposes. Statistical significance was established at $p<0.05$.

\section{Results}

\section{K10 Scores}

Regarding the score per item in K10, item 5 [during the last 30 days, how often did you feel restless or 
fidgety?] presented the highest average $(M=2.4$; $S D=$ 1.09), followed by items 2 [during the last 30 days, how often did you feel nervous?] $(M=2.3$; $S D=1.06)$, and 9 [during the last 30 days, how often did you feel that everything was an effort?] $(M=2.2 ; S D=1.30)$. The lowest mean $(M=1.5 ; S D=0.98)$ was observed in item 8 [during the past 30 days, how often did you feel so depressed that nothing could cheer you up?] (Table 1).

Validity Evidence Based on the Internal Structure: Exploratory Factor Analysis

Initially, it was observed that the Kaiser-MeyerOlkin (KMO) test was considered acceptable (0.91) and Bartlett's sphericity test was statistically significant $\left(\chi^{2}(45)=3580,9 ; p<0.001\right)$, confirming the scale's factorability. The results of the PA indicated the scale as unifactorial, corroborating the indicators of unidimensionality $(\mathrm{UniCo}=0.986 ; \mathrm{ECV}=0.899 ; \mathrm{MIREAL}=$ 0.233), which proved to be the best structural solution for the K10. The only factor presented by the scale was responsible for $69.9 \%$ of the explanatory variance. Regarding the factorial loads of the items, an average of $0.76(S D=0.10)$ of the saturation value was obtained and maximum values were observed in item 8 (0.91) and minimum, in item 9 (0.64).

Regarding its reliability, the K10 showed $\alpha$ equal to 0.93 . The adjustment and reliability indices showed values considered acceptable, namely: RMSEA = 0.092 , CFI $=0.985$, and NNFI $=0.981$. The values of reliability, adjustment and reliability are shown in Table 1.

Validity Evidence based on Relation to Other Variables: K-10 and PSS-10

The result of the correlation matrix between the total score of the K10 (10 items) and the PSS-10 indicated a positive and statistically significant association ( $\varrho=0.634 ; p<0.001)$, indicating that the higher the symptoms of distress, the greater the perceived stress.

\section{Social Distribution of Distress}

The average score of the total K10 score was 19.3 points $(S D=7.82 ;$ Min. $=10 ;$ Max. $=50)$. Considering the stratification as mild distress (from 10 to 15 points), moderate distress (from 16 to 21 points), high distress (from 22 to 29 points), and very high distress (from 30 to 50 points), it was observed that in general participants showed symptoms of moderate distress. Regarding the levels of distress presented by the sample, it was observed that $41.8 \%(n=300)$ of the respondents indicated mild distress, $28.4 \%(n=203)$ indicated moderate distress, $16.6 \%(n=119)$ showed high distress, and 13.2\% ( $n=95)$ obtained scores for very high distress.

A statistically significant difference was found when comparing scores between the sexes $(U=69.34 ; p$ $=0.003)$, so that women had a higher mean and median $(M=19.7 ; S D=7.66 ; M d=18 ;$ Min. $=10 ;$ Max. $=48)$

Table 1.

Means, standard deviations, factor loads and communalities of K10 items

\begin{tabular}{llll}
\hline K10 Items & $M(S D)$ & $\lambda$ & $h^{2}$ \\
For the last 30 days how often have you felt... & $2.2(1.15)$ & 0.68 & 0.46 \\
1. ... exhausted without a good reason? & $2.3(1.06)$ & 0.66 & 0.44 \\
2. ... nervous? & $1.5(0.97)$ & 0.85 & 0.73 \\
3. ... so nervous that nothing could soothe you? & $1.6(1.01)$ & 0.79 & 0.63 \\
4. ... hopeless? & $2.4(1.09)$ & 0.64 & 0.41 \\
5. ... restless or fidgety? & $1.7(1.09)$ & 0.77 & 0.60 \\
6. ... so restless that you couldn't sit still? & $1.8(1.05)$ & 0.86 & 0.74 \\
7. ... depressed? & $1.5(0.98)$ & 0.91 & 0.84 \\
8. ... so depressed that nothing could cheer you up? & $2.2(1.30)$ & 0.64 & 0.41 \\
9. ... that everything was an effort? & $1.5(1.04)$ & 0.81 & 0.66 \\
10.... worthless? & & & \\
\hline
\end{tabular}

Notes. $M=$ median; $S D=$ standard deviation; $\lambda=$ factor load; $h^{2}=$ communalities. Indicators of reliability and fit: Cronbach's alpha (0.930); RMSEA (0.092); CFI (0.985); NNFI (0.981). Unidimensional indicators: UniCo (0.986); ECV (0.899); MIREAL (0.233). 
than $\operatorname{men}(M=18.7 ; S D=8.01 ; M d=16 ;$ Min. $=10$; Max. $=50)$. There was also a statistically significant difference in relation to the presence of chronic disease, since individuals who reported suffering from some chronic disease $(U=51.62 ; p<0.001)$ had a higher mean and median $(M=23.2 ; S D=9.72 ; M d=21 ;$ Min . $=10 ;$ Max. $=50)$ compared to those without chronic diseases $(M=18.3 ; S D=6.99 ; M d=16 ;$ Min. $=10$; Max. = 50). Similarly, users of controlled medication $(U=49.43 ; p<0.001)$ had a higher mean and median $(M=23.2 ; S D=9.98 ; M d=21 ;$ Min. $=10 ;$ Max. $=50)$ than that those who did not use medication $(M=18.4$; $S D=6.95 ; M d=16 ;$ Min. $=10 ;$ Max. = 50). Respondents who did not work had a higher mean and median $(M=20.2 ; S D=7.79 ; M d=19 ;$ Min. $=10 ;$ Max. $=50)$ in the K10 than those who did $(M=19.0 ; S D=7.82$; $M d=16 ;$ Min. $=10 ;$ Max. $=48)$, also showing statistically significant results $(U=36.57 ; p=0.017)$. Finally, the comparison of means in the variable skin color $(U$ $=47.38 ; p=0.072)$ was borderline, so that non-whites $(M=19.6 ; S D=8.05 ; M d=17 ;$ Min. $=10 ; \operatorname{Max} .=50)$ had a higher mean and median than whites $(M=18.4$; $S D=7.14 ; M d=16 ; \operatorname{Min} .=10 ; \operatorname{Max} .=42)$. About the effect size, the differences in mean regarding the variable sex $(d=0.08)$, skin color $(d=0.06)$, and paid work $(d=0.09)$ were considered insignificant. In turn, the effect size of the differences in the mean of the variables chronic disease $(d=0.20)$ and use of controlled medication $(d=0.19)$ were considered weak. The correlation between distress and age was not statistically significant $(\varrho=-0.033 ; p=0.370)$.

\section{Discussion}

The present study aimed to analyze the validity evidence and accuracy of the Kessler Psychological Distress Scale (K10) in a Brazilian sample, specifically analyzing its factor structure and internal consistency and evaluating validity evidence based on the relationship with other variables using the PSS-10. It also aimed to present the social distribution of distress in the present sample. As for the factorial structure of K10, the unidimensionality of the scale was confirmed, a structure that has been pointed out as the most adequate by other studies over the years (Drapeau et al., 2012). It is understood that the unidimensionality of an instrument is related to good accuracy in measuring the observed variable (Pasquali, 2011) and, when displaying a singlefactor structure, it is assumed that all items on the scale refer to the same dimension of a construct; in this case, psychological distress. The cohesion of the variable studied and its reliability for use in future investigations was then ratified.

The reliability and internal consistency of the K10 achieved excellent Cronbach's Alpha (Damásio, 2012). This result corroborates the internal consistency values presented by the original validation of the scale (Kessler et al., 2002) and studies conducted in other countries (Donker et al., 2010; Sakurai et al., 2011; Terrez et al., 2011). This finding demonstrates the reliability of the scale in the present sample and suggests stability regarding future applications, also contributing to the presentation of validity evidence in measures in Psychology. As for the relationship with other variables, other studies also correlated the K10 with instruments to measure general health, such as depression and anxiety scales, confirming a significant relationship (Arnaud et al., 2010; Brenlla \& Aranguren, 2010; Easton et al., 2017) and, consequently, the applicability of K10 to measure such constructs. In the present investigation, a positive and statistically significant correlation was observed between K10 and PSS-10, corroborating the hypothesis that the higher the symptoms of distress, the higher the perceived stress.

As for the social distribution, mild to moderate distress rates were observed in the sample, which is close to the results found in validation studies of the scale with several populations (Easton et al., 2017; Pereira et al., 2017; Vasiliadis et al., 2015). Regarding the comparison of means between samples, other investigations found similar results to those in the present study $(M=$ 19.3), namely: mean 21.7 points in a Palestinian sample (Easton et al., 2017), 20.5 points in Portuguese individuals (Pereira et al., 2017), 17.9 points in an Argentine population sample (Brenlla \& Aranguren, 2010), 17.6 points in a Canadian sample (Vasiliadis et al., 2015), and 16.7 points in a rural random sample from Bangladesh (Uddin, Islam, \& Al Mahmud, 2018). It is observed that there is similar evidence across all continents regarding distress, even in different populations and types of sample. These findings indicate that, although there is no consensus in the literature regarding the average K10 score in global terms, this phenomenon has shown similar averages worldwide.

As observed in the literature, the findings of this research indicated that women had higher levels of distress than men (Anderson et al., 2013; Brenlla \& Aranguren, 2010; Byles et al., 2014; Caron et al., 2012; Enticott et al., 2017; Mouzon et al., 2016; Terrez et al., 2011; Vasiliadis et al., 2015; Weissman, Pratt, Miller, \& 
Parker, 2015). In general, several individual and external variables emerged as risk factors for the higher incidence of depressive disorders in women, namely: rumination, neuroticism, low social support, low marital satisfaction, stressful life events, divorce, parental loss, among others (Kendler \& Gardner, 2014; Kuehner, 2016). Anyhow, there seems to be a certain consensus when it is mentioned that women tend to suffer more impact than men in certain situations - especially those influenced by issues culturally associated with sexism or patriarchy -, which can make them more susceptible to greater stressful burdens and, consequently, higher levels of psychological suffering (American Psychiatric Association [APA], 2014; Byles et al., 2014; Kendler \& Gardner, 2014; Kuehner, 2016).

The presence of chronic diseases, the use of controlled drugs and the absence of paid work were variables that also showed relevance with regard to distress. Distress has been linked to cardiovascular problems and diabetes (Byles et al., 2014; Weissman et al., 2015), lung diseases (Weissman et al., 2015), among others. The presence of a chronic disease alone causes significant wear and, associated with psychological suffering, there is a risk of further aggravating both conditions, since one condition can exacerbate the existence of the other (Anderson et al., 2013; Byles et al., 2014; Lee et al., 2015). With regard to the use of controlled medications and the absence of paid work, evidence also points to such relationships (Byles et al., 2014; Enticott et al., 2017), reinforcing the findings of this investigation.

In a literature review conducted by Barnes and Bates (2017), several studies indicated skin color (race or ethnicity) as a relevant variable for the presence of distress, so that in 42 of the 45 comparisons, black people showed higher levels of distress than whites. In the present investigation, a result of borderline statistical relevance was observed when comparing whites and non-whites. However, it was corroborated that nonwhites had higher levels of distress. This finding can be understood due to health inequities, considering that skin color has been associated with the exclusion and marginalization of minorities and the discrepancy in access to health and the resources essential for human development (Faro \& Pereira, 2011).

In summary, we observed in this investigation that the K10 presented a single factor structure, as well as internal reliability and consistency indices considered excellent, corroborating international findings in relation to the scale's precision and reliability indices. Regarding the social distribution of distress, we observed higher levels of distress in women, patients with chronic diseases, users of controlled drugs and unemployed people or participants, pointing to the need for greater health care for these populations.

As limitations, it is evident the fact that the sample consisted only of residents of the municipality of Aracaju, State of Sergipe, despite having the positive characteristic of being constituted by a systematic household collection. Therefore, it is suggested that future administrations of the K10, as well as eventual analyses of the psychometric qualities of the scale, be conducted in other Brazilian states and / or regions, in order to provide more comparable national parameters. Furthermore, we highlight the relevance of analyzing the criterion validity of the K10 stratification in Brazil, since, although this form may be used as a means of interpreting the scores, there is a lack of investigations that reinforce or even attest to the differentiation in vulnerability or severity of clinical conditions, since it is based on progressive diagnostic strata of distress.

Finally, until then, there was no knowledge of Brazilian studies presenting validity evidence of the K10. By means of an Exploratory Factor Analysis, the present investigation proposed to fill this gap. We concluded that the K10 proved to be accurate and with robust psychometric properties for tracking distress in the general population, and it is noteworthy that it is a free, short, and easy to use instrument. In other words, it is interesting to use in research and / or monitoring of general mental health information of clinical and non-clinical groups.

\section{References}

American Psychiatric Association [APA]. (2014). Diagnostic and Statistical Manual of Mental Disorders: DSM-5. Porto Alegre: Artmed.

Andersen, L. S., Grimsrud, A., Myer, L., Williams, D. R., Stein, D. J., \& Seedat, S. (2011). The psychometric properties of the K10 and K6 scales in screening for mood and anxiety disorders in the South African Stress and Health study. International Journal of Methods in Psychiatric Research, 20(4), 215-223. doi: 10.1002/mpr.351

Anderson, T. M., Sunderland, M., Andrews, G., Titov, N., Dear, B. F., \& Sachdev, P. S. (2013). The 10item Kessler Psychological Distress Scale (K10) as a screening instrument in older individuals. The 
American Journal of Geriatric Psychiatry, 21(7), 596606. doi: 10.1097/JGP.0b013e318252e7a7

Andrews, G., \& Slade, T. (2001). Interpreting scores on the Kessler Psychological Distress Scale (K10). Australian and New Zealand Journal of Public Health, 25(6), 494-497. doi: 10.1111/j.1467-842X.2001. tb00310.x

Arnaud, B., Malet, L., Teissedre, F., Izaute, M., Moustafa, F., Geneste, J., Schmidt, J., Llorca, P., Brousse, G. (2010). Validity study of Kessler's psychological distress scales conducted among patients admitted to French emergency department for alcohol consumption-related disorders. Alcoholism: Clinical and Experimental Research, 34(7), 1235-1245. doi: 10.1111/j.1530-0277.2010.01201.x.

Baik, S. H., Fox, R. S., Mills, S. D., Roesch, S. C., Sadler, G. R., Klonoff, E. A., \& Malcarne, V. L. (2019). Reliability and validity of the Perceived Stress Scale-10 in Hispanic Americans with English or Spanish language preference. Journal of Health Psychology, 24(5), 628-639. doi: 10.1177/1359105316684938

Barnes, D. M., \& Bates, L. M. (2017). Do racial patterns in psychological distress shed light on the BlackWhite depression paradox? A systematic review. Social Psychiatry and Psychiatric Epidemiology, 52, 913928. doi: 10.1007/s00127-017-1394-9

Bougie, E., Arim, R. C., Kohen, D. E., \& Findlay, L. C. (2016). Validation of the 10-item Kessler Psychological Distress Scale (K10) in the 2012 Aboriginal Peoples Survey. Statistics Canada - Health Reports, 27, 3-10. Recuperado de https://www150. statcan.gc.ca/n1/en/pub/82-003-x/2016001/ article/14307-eng.pdf?st=boTqZFqG

Brenlla, M. E., \& Aranguren, M. (2010). Adaptación argentina de la escala de malestar psicológico de Kessler (K10). Revista de Psicología de la Pontificia Universidad Católica del Perú, 28(2), 311-342. Recuperado de http://revistas.pucp.edu.pe/index.php/ psicologia/article/view/1464

Brooks, R. T., Beard,J., \& Steel,Z. (2006). Factor structure and interpretation of the K10. Psychological Assessment, 18, 62-70. doi: 10.1037/1040-3590.18.1.62.

Byles, J. E., Robinson, I., Banks, E., Gibson, R., Leigh, L., Rodgers, B., . . Jorm, L. (2014). Psychological distress and comorbid physical conditions: Disease or disability? Depression and Anxiety, 31, 524-532. doi: $10.1002 /$ da.22162
Caron, J., Fleury, M.-J., Perreault, M., Crocker, A., Tremblay, J., Tousignant, M., ... Daniel, M. (2012). Prevalence of psychological distress and mental disorders, and use of mental health services in the epidemiological catchment area of Montreal South-West. BMC Psychiatry, 12, 183. doi: 10.1186/1471-244X-12-183

Damásio, B. F. (2012). Uses of exploratory factorial analysis in psychology. Avaliação Psicológica, 11(2), 213-228. Retrieved from http://pepsic. bvsalud.org/scielo.php?script=sci_abstract\&pi$\mathrm{d}=$ S1677-04712012000200007

Damásio, B. F., \& Dutra, D. F. (2017). Exploratory factor analysis: A tutorial with Factor software [Análise fatorial exploratória: Um tutorial com o software Factor]. In B. F. Damásio \& J. C. Borsa (Orgs.), Development manual for psychological tools [Manual de desenvolvimento de instrumentos psicológicos] (pp. 241-266). São Paulo: Vetor.

Donker, T., Comijs, H., Cuijpers, P., Terluin, B., Nolen, W., Zitman, F., \& Penninx, B. (2010). The validity of the Dutch K10 and extended K10 screening scales for depressive and anxiety disorders. Psychiatry Research, 176, 45-50. doi: 10.1016/j. psychres.2009.01.012

Drapeau, A., Marchand, A., \& Beaulieu-Prévost, D. (2012). Epidemiology of psychological distress. In L. Labate (Ed.), Mental illnesses: Understanding, prediction and control (pp. 105-134). Rijeka, Croatia: InTech.

Easton, S. D., Safadi, N. S., Wang, Y., \& Hasson, R. G. (2017). The Kessler psychological distress scale: Translation and validation of an Arabic version. Health and Quality of Life Outcomes, 15, 215. doi: 10.1186/s12955-017-0783-9

Enticott, J. C., Lin, E., Shawyer, F., Russell, G., Inder, B., Patten, S., \& Meadows, G. (2017). Prevalence of psychological distress: How do Australia and Canada compare? Australian \& New Zealand Journal of Psychiatry, 52(3), 227-238. doi: 10.1177/0004867417708612

Faro, A. (2015a). Stress and distress: study with faces scale in Aracaju (SE) [Estresse e distresse: Estudo com a Escala de Faces em Aracaju (SE)]. Temas em Psicologia, 23(2), 341-354. doi: 10.9788/ TP2015.2-08 
Faro, A. (2015b). Confirmatory factor analysis of three versions of the Perceived Stress Scale (PSS): a population-based study [Análise Fatorial Confirmatória das três versões da Perceived Stress Scale (PSS): Um estudo populacional]. Psicologia: Reflexão e Crítica, 28, 21-30. doi: 10.1590/1678-7153.201528103

Faro, A., \& Pereira, M. E. (2011). Race, racism and health: the social inequality of the distribution of stress [Raça, racismo e saúde: A desigualdade social da distribuição do estresse]. Estudos de Psicologia, 16(3), 271-278. doi: 10.1590/S1413-294X2011000300009

Faro, A., \& Pereira, M. E. (2013). Stress: Narrative Review of Conceptual Evolution, Theoretical and Methodological Perspectives [Estresse: Revisão narrativa da evolução conceitual, perspetivas teóricas e metodológicas]. Psicologia, Saúde \& Doenças, 14(1), 78-100. Retrieved from http://www. scielo.mec.pt/scielo.php?script=sci_arttext\&pi$\mathrm{d}=$ S1645-00862013000100006\&lng=pt\&tlng=pt.

Ferrando, P. J., \& Lorenzo-Seva, U. (2017). Program FACTOR at 10: Origins, development and future directions. Psicothema, 29(2), 236-240. doi: 10.7334/ psicothema2016.304

Furukawa, T. A., Kawakami, N., Saitoh, M., Ono, Y., Nakane, Y., Nakamura, Y., . . Kikkawa, T. (2010). The performance of the Japanese version of the K6 and K10 in the World Mental Health Survey Japan. International Journal of Methods in Psychiatric Research, 17(3), 152-158. doi: 10.1002/mpr.257

Gomes-Oliveira, M. H., Gorenstein, C., Lotufo Neto, F., Andrade, L. H., \& Wang, Y. P. (2012). Validation of the Brazilian Portuguese version of the Beck Depression Inventory-II in a community sample. Revista Brasileira de Psiquiatria, 34, 389-394. doi: 10.1016/j.rbp.2012.03.005

Kendler, K. S., \& Gardner, C. O. (2014). Sex differences in the pathways to major depression: A study of opposite-sex twin pairs. American Journal of Psychiatry, 171, 426-435. doi: 10.1176/appi. ajp.2013.13101375

Kessler, R. C., Andrews, G., Colpe, L. J., Hiripi, E., Mroczek, D. K., Normand, S.-L. T., Walters, E. E., \& Zaslavsky, A. M. (2002). Short screening scales to monitor population prevalences and trends in nonspecific psychological distress. Psychological Medicine, 32, 959-76. doi: 10.1017/S0033291702006074
Kessler, R. C., Barker, P. R., Colpe, L. J., Epstein, J. F., Gfroerer, J. C., Hiripi, E., . . . Zaslavsky, A. M. (2003). Screening for serious mental illness in the general population. Archives of general psychiatry, 60, 184-89. doi: 10.1001/archpsyc.60.2.184

Klein, E. M., Brähler, E., Dreier, M., Reinecke, L., Müller, K. W., Schmutzer, G., Wölfling, K., \& Beutel, M. E. (2016). The German version of the Perceived Stress Scale - psychometric characteristics in a representative German community sample. BMC Psychiatry, 16,159. doi: 10.1186/s12888-016-0875-9

Kuehner, C. (2016). Why is depression more common among women than among men? The Lancet Psychiatry, 4(2), 146-158. doi: 10.1016/ S2215-0366(16)30348-0

Laros, J. A. (2012). The use of factor analysis: Some guidelines for researchers $[\mathrm{O}$ uso da análise fatorial: Algumas diretrizes para pesquisadores]. In L. Pasquali (Org.), Factor analysis for researchers [Análise fatorial para pesquisadores] (pp. 141-160). Brasília: LabPAM Saber e Tecnologia.

Leal, E. M., Delgado, P. G. G., Mann, R., Strike, C., Brands, B., \& Khenti, A. (2012). Comorbidity study: psychological distress and drug abuse among people in treatment centres, Macaé - Brasil [Estudo de comorbidade: Sofrimento psíquico e abuso de drogas em pessoas em centros de tratamento, Macaé - Brasil]. Texto \& Contexto Enfermagem, 21(esp), 96-104. doi: 10.1590/ S0104-07072012000500013

Lee, D. Y., Kim, E., \& Choi, M. H. (2015). Technical and clinical aspects of cortisol as a biochemical marker of chronic stress. BMB Reports, 48(4), 209216. doi: 10.5483/BMBRep.2015.48.4.275

Lorenzo-Seva, U. (2013). Why rotate my data using Promin? (Technical Report). Departamento de Psicologia, Universidade Rovira e Virgili, Tarragona. Retrieved from http://psico.fcep.urv.cat/utilitats/factor/

Machado, W. L., Damásio, B. F., Borsa, J. C., \& Silva, J. P. (2014). Dimensionality of the Perceived Stress Scale (PSS-10) for school teachers [Dimensionalidade da escala de estresse percebido (Perceived Stress Scale, PSS-10) em uma amostra de professores]. Psicologia: Reflexão e Crítica, 27, 38-43. doi: 10.1590/S0102-79722014000100005

Mota, M. L., \& Faro, A. (2018). Prevalence and socialdistribution of distress in a population sample 
[Prevalência e distribuição social do distresse em uma amostra populacional]. Interamerican Journal of Psychology (IJP), 52(3), 389-398. doi: 10.30849/ rip \%20ijp.v52i3.496

Mouzon, D. M., Taylor, R. J., Nguyen, A. W., \& Chatters, L. M. (2016). Serious psychological distress among African Americans: Findings from the National Survey of American Life. Journal of Community Psychology, 44(6), 765-780. doi: 10.1002/jcop.21800

National Comorbidity Survey (n. d). K10 and K6 scales. Retrieved from http://www.hcp.med.harvard. edu/ncs/k6_scales.php

Pasquali, L. (2011). Psychometrics: Test theories in Psychology and Education [Psicometria: Teorias dos testes na Psicologia e na Educação]. Petrópolis: Vozes.

Pereira, A., Jardim, J., Monteiro, S., Oliveira, C. A., Vagos, P., \& Bártolo, A. (2017). Reliability and Factor Structure of the 10-item Kessler Psychological Distress Scale (K10) among Portuguese adults [Confiabilidade e Estrutura Fatorial da Escala de Distress Psicológico de Kessler de 10 itens (K10) entre adultos Portugueses]. Ciência \& Saúde Coletiva. Retrieved from http://www. cienciaesaudecoletiva.com.br/artigos/confiabilidade-e-estrutura-fatorial-da-escala-de-distress-psicologico-de-kessler-de-10-itens-k10-entre-adultos-portugueses $/ 16237$ ? id $=16237$

Reis, R. S., Hino, A. A. F, \& Rodriguez-Añez, C. R. (2010). Perceived Stress Scale: Reliability and validity study in Brazil. Journal of Health Psychology, 15. 107-114. doi: 10.1177/1359105309346343

Sakurai, K., Nishi, A., Kondo, K., Yanagida, K., \& Kawakami, N. (2011). Screening performance of $\mathrm{K} 6 / \mathrm{K} 10$ and other screening instruments for mood and anxiety disorders in Japan. Psychiatry and Clinical Neurosciences, 65, 434-441. doi: 10.1111/j.1440-1819.2011.02236.x

Sampasa-Kanyinga, H., Zamorski, M. A., \& Colman, I. (2018). The psychometric properties of the 10item Kessler Psychological Distress Scale (K10) in Canadian military personnel. PLoS ONE, 13(4), e0196562. doi: 10.1371/ /journal.pone.0196562

Sireci, S. G., \& Sukin, T. (2013). Test validity. In K. F. Geisenger (Ed.), APA Handbook of Testing and Assessment in Psychology (pp. 61-84). Washington, D. C.: American Psychological Association. Vol 1.
St-Pierre, M., Sinclair, I., Elgbeili, G., Bernard, P., \& Dancause, K. N. (2019). Relationships between psychological distress and health behaviors among Canadian adults: Differences based on gender, income, education, immigrant status, and ethnicity. SSM - Population Health, 7, 100385. doi: 10.1016/j. ssmph.2019.100385

Sunderland, M., Mahoney, A., \& Andrews, G. (2012). Investigating the Factor Structure of the Kessler Psychological Distress Scale in Community and Clinical Samples of the Australian Population. Journal of Psychopathology and Behavioral Assessment, 34, 253-259. doi: 10.1007/s10862-012-9276-7

Terrez, B. E. V., Salcedo, V. V., Estrada, C. R., Romero, J. P., \& Sotres, J. C. (2011). Validación de la escala Kessler 10 (K-10) en la detección de depresión y ansiedad en el primer nivel de atención: Propiedades psicométricas. Salud Mental, 34(4), 323-331. Retrieved from http://www.scielo.org.mx/scielo.php? script=sci_arttext\&pid =S0185-33252011000400005

Uddin, M. N., Islam, F. M. A., Al Mahmud, A. (2018). Psychometric evaluation of an interview administered version of the Kessler 10-item questionnaire (K10) for measuring psychological distress in rural Bangladesh. BMJ Open, 8: e022967. doi: 10.1136/ bmjopen-2018-022967

Vasiliadis, H.-M., Chudzinski, V., Gontijo-Guerra, S., \& Préville, M. (2015). Screening instruments for a population of older adults: The 10-item Kessler Psychological Distress Scale (K10) and the 7-item Generalized Anxiety Disorder Scale (GAD7). Psychiatry Research, 228, 89-94. doi: 10.1016/j. psychres.2015.04.019

Weissman, J., Pratt., L. A., Miller, E. A., \& Parker, J. D. (2015). Serious psychological distress among adults: United States, 2009-2013. NCHS Data Brief, 203. Retrieved from http://pdfs.semanticscholar. org/ae33/3d30ac22aa561b82227938d40302341c1 eb2.pdf

Zenebe, Y., \& Necho, M. (2019). Socio-demographic and substance-related factors associated with mental distress among Wollo university students: institution-based cross-sectional study. Annals of General Psycbiatry, 18, 28. doi: 10.1186/s12991-019-0252-4

Recebido em: 12/05/2019 Reformulado em: 14/05/2020 Aprovado em: 21/05/2020 
About the authors:

Brenda Fernanda Pereira da Silva has a Master's degree in Psychology from the Post-Graduate Program in Psychology at the Federal University of Sergipe (PPGPSI-UFS) and B.A. in Psychology from the Federal University of Sergipe (UFS).

ORCID: http://orcid.org/0000-0003-1139-0342

E-mail:brenda_iga@yahoo.com.br

Laís Santos-Vitti is a doctoral student at the Post-Graduate Program in Psychology at the Pontifical Catholic University of Campinas (PUC-Campinas), Master in Social Psychology at the Post-Graduate Program in Psychology at the Federal University of Sergipe (PPGPSI-UFS) and has a CAPES scholarship holder.

ORCID: http://orcid.org/0000-0001-7625-9228

E-mail: laiss.santos9597@gmail.com

André Faro is a PhD in Psychology from the Federal University of Bahia (UFBA), has a postdoctoral degree from Johns Hopkins University (JHU, Bloomberg School of Public Health), and is a professor of Psychology at the Federal University of Sergipe (UFS). He is a CNPq researcher (level 2).

ORCID: http://orcid.org/0000-0002-7348-6297

E-mail: andre.faro.ufs@gmail.com

\section{Contact:}

Department of Psychology, DPS

Av. Marechal Rondon, s/n, Jardim Rosa Elze

São Cristóvão-SE, Brasil

CEP: 49100-000 